\title{
OBJETIVOS Y LÍNEAS DE ACCIÓN PARA LA PASTORAL MAPUCHE ${ }^{1}$
}

\section{A. Fundamentación}

1. Cristo envió a su Iglesia a anunciar el Evangelio a todos los hombres, a todos los pueblos. Puesto que cada hombre nace en el seno de una cultura, la Iglesia busca alcanzar, con su acción evangelizadora, no solamente al individuo sino a la cultura del pueblo (EN19-20, DP 394). Considerando la pluralidad cultural del Vicariato, el Departamento de Pastoral Mapuche surge como iniciativa frente al desafío de "buscar los caminos apropiados de evangelización" del pueblo mapuche en esta región. ${ }^{2}$

2. A través de la práctica pastoral es posible reconocer la complejidad del escenario religioso mapuche en la Araucania. Encontramos hermanos mapuches que viven su tradición religiosa original en relación con su fe cristiana. Hay otros que optan por no establecer esta relación. Hay también hermanos que viven su fe en Cristo en una cierta ruptura con su cultura tradicional. Otros están buscando caminos para vivir su fe en Cristo a partir de su propia cultura. Esto está en directa relación con la diversidad de ofertas religiosas y de iglesias que demandan la adhesión mapuche. Esta complejidad exige buscar respuestas adecuadas a cada realidad.

3. Es claro que la evangelización no se reduce a una acción pastoral en el ámbito religioso. Desde el momento que se pretende evangelizar "no de una manera decorativa, como con un barniz superficial, sino de manera vital, en profundidad y hasta sus mismas raíces - la cultura y las culturas del hombre" (EN 20), se hace necesario desarrollar una pastoral integral que respete la complejidad de la cultura mapuche.

4. Existe la tendencia a reducir la problemática mapuche a la pérdida de su identidad cultural. Se afirma que ya no se habla el idioma, que no se vive en rucas, que no se hace más nguillatún y sigue así la lista de elementos culturales que se están perdiendo. Pero el problema es más complejo. La pérdida de identidad es el síntoma de una crisis más profunda, que es la desestructuración social de las comunidades. La integración forzada e injusta de las comunidades a la sociedad nacional a partir de la "pacificación" y las múltiples y constantes intervenciones externas, han conducido a los mapuches a entender que su situación de miseria y

1 El documento que presentamos a continuación contiene la Fundamentación, la Propuesta pastoral y los objetivos y líneas de acción, del Departamento de Pastoral Mapuche del Vicariato Apostólico de la Araucania. Agradecemos a su Asesor, el P. FERNANDO DIAZ, por esta colaboración. 
marginación se debe justamente a su diferencia cultural. Luego, la tendencia ha sido el desarrollo de una valoración negativa de su propia cultura y con ello el progresivo deterioro de su estructura social.

5. Una evangelización que no busca la reintegración social de la comunidad mapuche, se convierte en un factor más de desintegración social, en contradicción clara con los objetivos de la propuesta de la evangelización inculturada (SD 248). La evangelización del pueblo mapuche requiere del protagonismo de los propios mapuches, no solo individualmente sino como pueblo con cultura propia.

\section{B. Propuesta pastoral}

Por todo lo anterior, este departamento se propone realizar una acción pastoral orientada a establecer una relación nueva con las comunidades y organizaciones mapuches. Esta relación debe caracterizarse por ser un acompañamiento a las comunidades a partir del respeto y valoración de su cultura. Un aspecto fundamental debe ser el reconocimiento de sus autoridades tradicionales. Se trata de apoyar y defender como Iglesia el derecho de las comunidades a organizarse y a expresarse de acuerdo a su propia cultura. Evangelizar a partir de la cultura del pueblo mapuche significara ofrecer la Buena noticia del Reino de los Cielos y su justicia.

Del escenario religioso mapuche se desprenden dos líneas fundamentales: la evangelización inculturada y diálogo inter-religioso. En ambos se trata de acompañar desde y con el Evangelio las distintas realidades del pueblo mapuche en la Araucanía.

\section{Objetivos y líneas de acción}

\section{a) Acompañamiento y formación de personas}

Con relación a los mapuches cristianos, el objetivo es acompañarlos en su interés de establecer una relación fecunda entre su tradición mapuche y su experiencia cristiana, de modo que puedan vivir su fe en forma vital y en relación con su comunidad cultural.

Con relación a los mapuches no-cristianos, el objetivo es implementar el diálogo inter-religioso, de modo que la pluralidad religiosa sea un factor de enriquecimiento de la comunidad y no causa de división y desestructuración. Con relación a los no-mapuche, el objetivo es que desenvuelvan actitudes de respeto y de diálogo con la realidad mapuche. Esto significa que a partir de la fe cristiana sea posible abrirse a nuevas relaciones con el pueblo mapuche, mediante la que se puedan superar esquemas de dominación que contradicen la justicia del Reino.

\section{b) Acompañamiento y formación de comunidades y organizaciones}

Se trata de ayudar a las comunidades cristianas mapuches a relacionarse de modo que sean servidoras de su comunidad cultural y no causa de mayor desestructuración. Esto es especialmente importante en las comunidades que se celebran los ritos tradicionales o donde hay procesos de reconstitución de la estructura social de la comunidad. 
- En relación a las organizaciones, se trata de ofrecerles desde el evangelio, el apoyo y los servicios que les ayuden a comprometerse con su pueblo en la perspectiva de construir una sociedad más justa.

\section{c) Acompañamiento de los procesos sociales y desafío emergentes}

Se trata de atender a los procesos de cambio que está viviendo tanto la sociedad mapuche como la sociedad nacional, para poder ofrecer la iluminación teológica y los servicios pastorales y solidarios adecuados a las situaciones que lo requieran. Especial atención requieren los conflictos de tierra, de estudiantes, ecológicos, de migración y en general de los derechos de los pueblos indígenas.

- Se propone la constitución de un consejo pastoral ampliado que permita realizar análisis coyunturales correspondientes y otorgue elementos para elaborar la propuestas adecuadas. 